\title{
INTEGRATION AND COMPARISON OF CLOSE-RANGE SFM METHODOLOGIES FOR THE ANALYSIS AND THE DEVELOPMENT OF THE HISTORICAL CITY CENTER OF BETHLEHEM
}

\author{
S. Parrinello ${ }^{1}$, F. Picchio ${ }^{1}$ \\ ${ }^{1}$ DICAr, Department of Civil Engineering and Architecture, University of Pavia, Italy, \\ (sandro.parrinello@unipv.it, francesca.picchio@unipv.it)
}

\section{Commission II}

KEY WORDS: UAVs acquisition, Structure from Motion, Bethlehem, historical Cultural Heritage, reliable tests.

\begin{abstract}
:
The present paper illustrates a part of the methodological process of image-based acquisition developed for the documentation of the historical city center of Bethlehem, in the Middle East territory. The first mission of research activities, developed inside the international cooperation project "Management and control of urban growth for the development of heritage and improvement of life in the city of Bethlehem" (2018-2021), coordinated by University of Pavia in collaboration with the Municipality of Pavia and financed with the contribution of AICS (Italian Agency for Cooperation and Development), has been carried on through combined application of digital instruments, TLS and UAV, with the aim of developing "smart", low-cost and rapid execution procedures for the production of a reliable three-dimensional model of the historic city center. The paper shows the application of different photogrammetric survey campaigns in a portion of the historical town, acquisition problems and tests of morphometrical reliability of each output, in order to develop a general SfM database consisting of different definition levels of the photogrammetric models of historical city center.
\end{abstract}

\section{INTRODUCTION}

The connotation of the urban historical and cultural contexts is today subject to the constant production of interpretative forms and models, due to the continuous changing of the digital tools and procedures of data acquisition and processing. At the same time, the documentation of large scale territory is problematic for the existing gap between the output obtained with "traditional" aerial photogrammetry and terrestrial survey (TLS and SfM) (Lo Brutto, M., Garraffa, A. and Meli, P., 2014), which complicates the production of a reliable model of the townscape. With the aim to develop a methodological/ procedural system to codify and manage the urban complexity of an historical center, the research presents in this paper is moving to develop a model of Bethlehem historical city center, that can form the basis for generating analysis tools for a better comprehension of relationships between the space elements and their geometrical aspects. The development of an informative 3D model of the city wants to lay the foundation for improving the territorial governance of the Municipality of Bethlehem and the management of the city growth, thanks to a direct interaction between users and the digitized cultural heritage. The first survey campaign, performed in June 2018 by the team of DAda Laboratory of DICAr, Department of Civile Engineering and Architecture of Pavia University, concerned the experimentation of digital tools, range-based and imagebased, on part of the urban areas around the complex of the Nativity Church. Because of the complexity systems of each historical neighborhoods, parallel to the TLS, photogrammetric close range operations from UAS (unmanned aerial systems) has been carried out, combined with the data acquisition from the ground level, to test the efficacy and the metric reliability of the SfM methodology on a territorial scale (Parrinello and Picchio, 2014). This procedures has been aimed to develop a fast digital reconstruction of the townscape, characterized by 3D models defined of different datas and informations.

\section{RELATED WORKS}

The use of UAVs and drone remote sensing as platforms in digital survey (Tang and Shao, 2015) has been increased for the development of faster and lower cost survey in civilian, agricultural and environmental application. The use of small UAVs has changed the method of territorial image acquisition, implementing the quality of the objects acquired where a high resolution is requested. (Colomina and Molina 2014). The application of micro, mini and close range UAVs on Cultural Heritage field (Remondino et al. 2011) is documented by recent studies, in which the usefulness for detecting and monitoring cultural heritage features of historical buildings is underlined. For small detailed buildings, as historical buildings (Themistocleous et al., 2015; Caprioli et al. 2015), or archaeological sites (Rinaudo et al. 2012; Chiabrando et al. 2011), the research is quickly moving through the integration of methodologies and data obtained from TLS and close-range UAVs to define the starting point for the reconstruction of the environmental, urban or archaeological context. In particular, the aim is to obtain a metric reliable and textured 3D model of a large area or environment, that can be used for urban management but also for virtual valorization (Balletti et al. 2015). To reach this goal is necessary to exploit the potential of each acquisition methods and to combine the final outputs in a digital database, that can be implemented with different kind of information and digital data. The use of different drones for the acquisition of a portion of city center involves the tests on metric and geometric reliability of the different point cloud obtained (Friz et al, 2013) to develop a replicable method on the whole territorial context. Moreover, the use of drones is more and more indispensable in the case of critical areas (postearthquake scenarios or after war conflicts) whose morphological complexity, connected to the impossibility of completely accessing the spaces, doesn't allow the use of ground-based instruments (Dominici et al. 2017).

The research project developing in Bethlehem historical city center aims at testing the response of photogrammetric digital technologies applied in an extremely complex and heterogeneous urban fabric. The activities are focused on the 
definition, the test and the development of a methodological easily large scale replicable procedures. The defined workflow is oriented to optimize the best use of each photographic instrument, drones and reflex cameras, for the integration of terrestrial and aerial photogrammetry. The urban structure has been designed considering different shapes for the analysis of the morphological complexity. Specific contexts have been defined, related to environmental level of analysis (a hierarchy that link the architectural detail to the urban landscape): urban fronts, building units, aggregates-clusters and plots units, neighborhoods and areas.

\section{DEVELOPED METHODOLOGY}

\subsection{Definition of Bethlehem neighborhood case study}

The choice of an SfM integrated methodology, from UAVs and ground photogrammetry acquisition, is strongly bound by the complexity of the urban structure of the historic center of Bethlehem. The digital survey on such extended territory requires a fast procedure to cover the urban space reaching information on unaccessible areas. The goal is the elaboration of a reliable $3 \mathrm{D}$ model responding as much as possible to the place conformation, for the management and the control of the urban growth.

The neighborhood structure is constituted by extremely dense and heterogeneous area, composed by empty and full spaces. Each neighborhood is concentrically located around the Nativity complex and Manger Square and arranged on different terrain levels and gradually decrease in density towards the border of the town. The neighborhoods are constituted by building aggregates, called "clusters". Their shape is composed of regular but not neatly arranged architectural volumes, asymmetrically structured (Figure 1). The main front of the buildings could face an inner courtyard because of the urban stratification. Such plot units, bounded by buildings back side walls, are connected by narrow pedestrian paths.
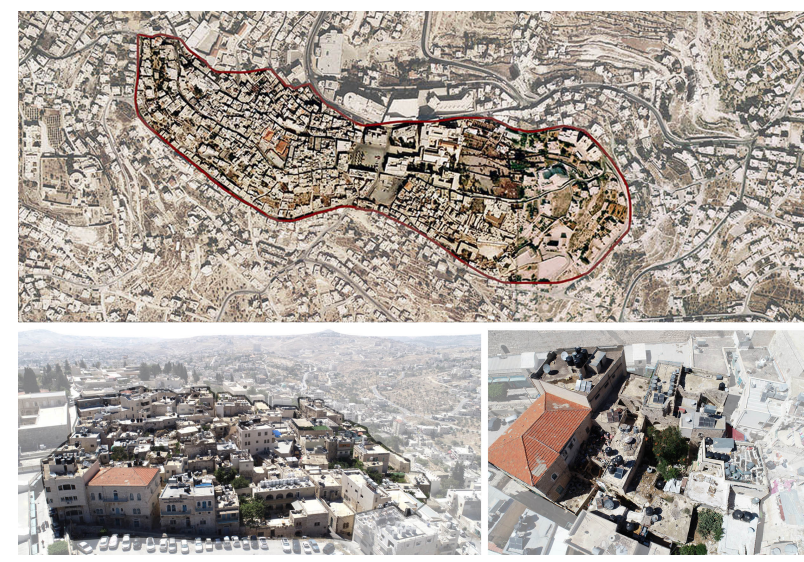

Figure 1: Bethlehem city center. The area identify by the documentation project and the morphology complexity of the historical neighborhood Al- Anatreh.

As a case study of the research has been chosen the Al-Anatreh quarter, a christian neighborhood characterize by the presence of crusader architecture. The structure of Anatreh neighborhood is consisting in seven clusters. In this area the stratification of building typologies is strongly presents. During the time, the simple crusader building units has been joint to other structures, forming complex volumes that nowadays constitutes the main stratified typologies system of the city center. The structures of the volumes are all constituted by characteristic Jerusalem yellow stones, that give a homogeneous organic aspect to the city, emphasizing the geometric volumes of the building blocks. The pedestrian paths, that split the clusters, are characterized by narrow alleys. The paths consist of long stairways, covered passages and outcrops. The boundary wall of each block unit is vertically animated by relationship between solids and voids that mark the rhythm of the building facade (Figure 2).

Those spatial characteristics imply the definition of a strategy for a detailed photographic close range acquisition from the ground. The SfM acquisition will be aimed at the optimization of SLR camera movement to generate chunks of high-density points and completeness of each surfaces.

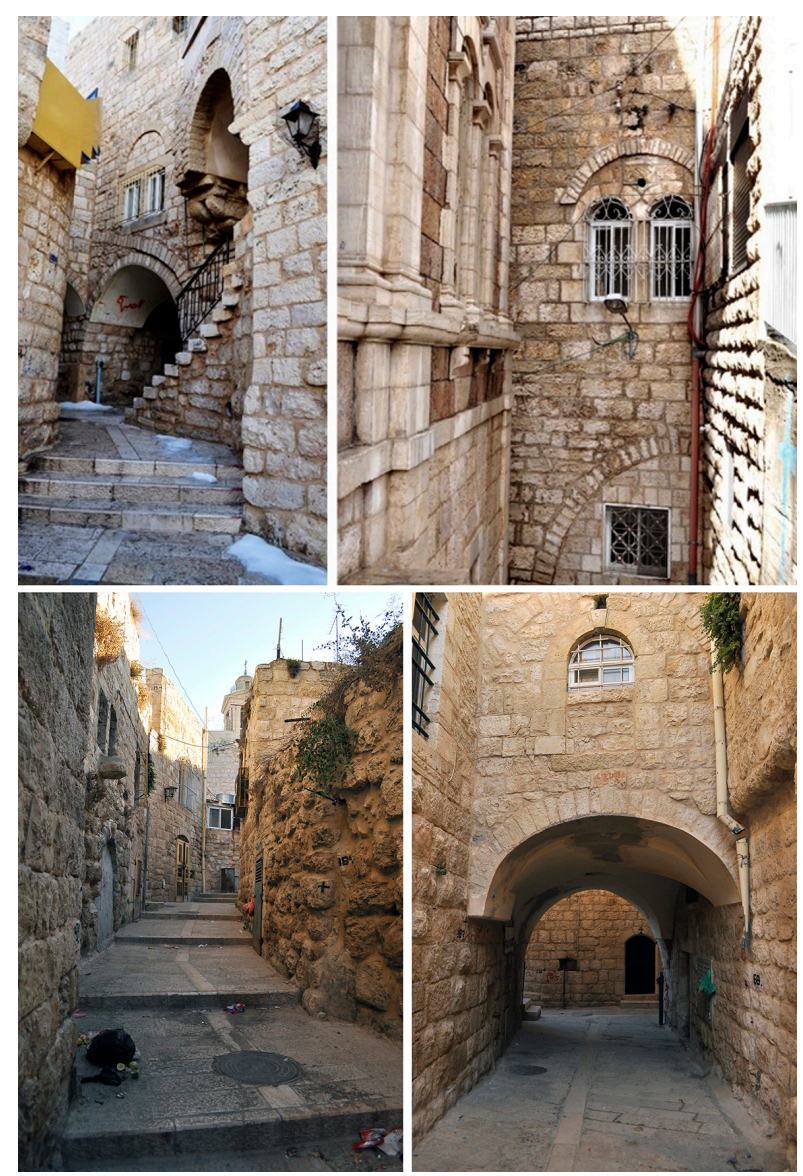

Figure 2: Inner paths of Al-Anatreh, analysis and strategy definition for close-range survey campaign acquisition from the ground.

At the same time, the presence of external elements, superfetations, visible metal antennas and plastic cisterns on the roofs considerably complicates the photographic acquisition planning of the buildings upper part. Inside the clusters courtyards, and often on the roofs, open landfills are present (Figure 3).
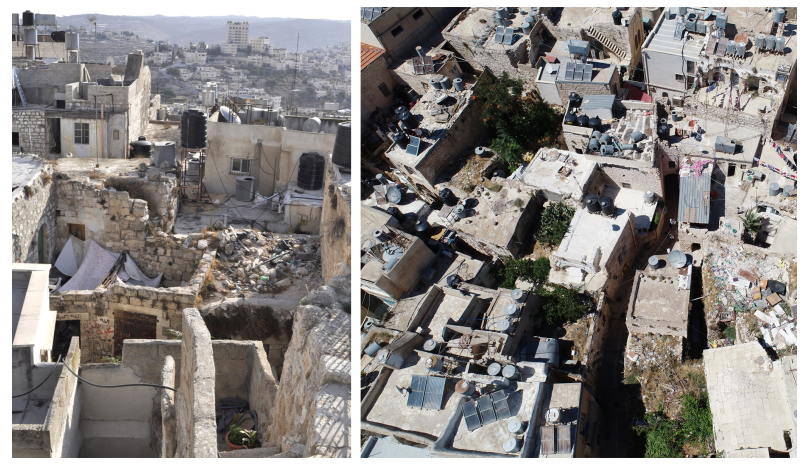

Figure 3: Landfills on roofs and courtyards. 
These dump phenomenas, that defaces the townscape, mostly occur with abandoned areas, inaccessible or dangerous cause at risk of structural collapse. To measure and survey that areas, the use of UAS is strongly recommended.

The preliminary morphological analysis of the townscape has proved to be fundamental in the planning of the use of imagebased equipment. The integration with range-based instruments (TLS) has been conduct for the reliability check of SfM point cloud, for the deformation analysis on the walls surfaces joint to a better understanding of the architectural details and, finally, for the integration of the missing data in those areas where TLS could not be conducted.

\subsection{Planning of Aerial and terrestrial image acquisition}

A first survey campaign (conducted in June 2018) has involved the use of TLS and UVAs for the acquisition of a huge portion of Bethlehem city center. The border of that area regards the historical city center, from the Nativity complex till the east side of the perimeter. The width of the area, its morphological complexity and the high presence of inaccessible zones led to the choice of using the drones as integrated tool of documentation activities. Therefore, the drone activity planning has been constrained by the need to obtain a point cloud of the highest data quality and density. The flight and shooting modes (Nex and Remondino, 2013) have also been structured with the aim of generating a database to integrate the missing parts of the Faro Cam 2 laser scanner point cloud. To perform an SfM photo campaign from drone, a DJI Phantom 4 Pro has been used as the main UAS for the creation of a territorial point cloud of the whole area. The first mission area has been divided into thirteen sub-systems (Figure 4), depending on the complexity of each neighborhood, but also on the on the performance of the instrument used (eg. flight time of the battery, weather conditions, constraints for the visibility of the APR operator).

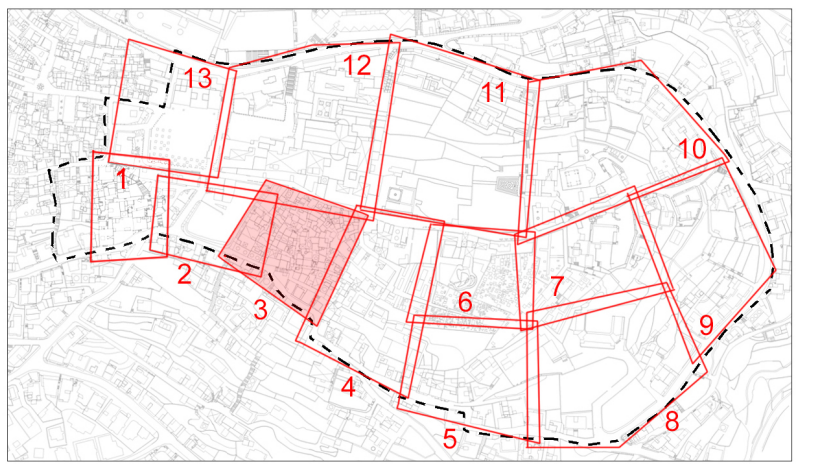

Figure 4: Subdivision plan of the first mission area.

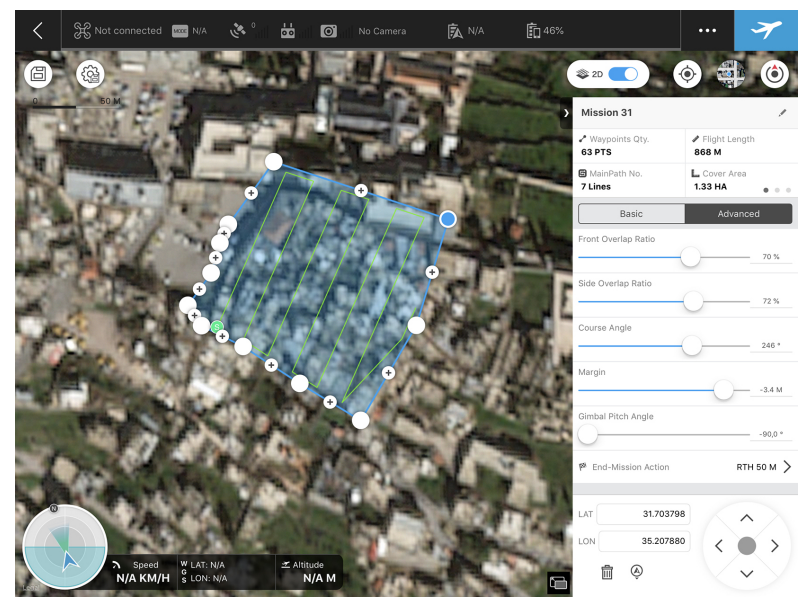

Figure 5: Editing flight mode parameters on DJI GSP.
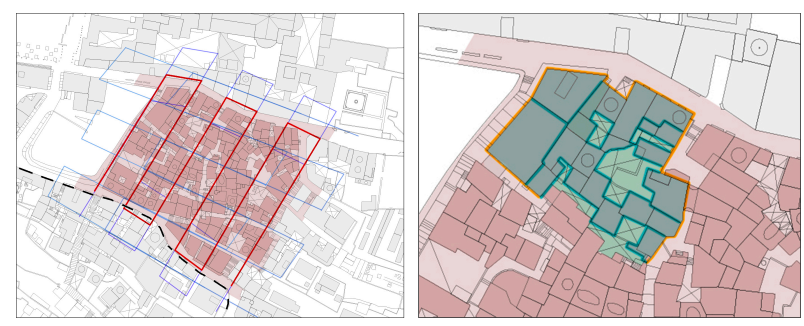

Figure 6: On the left, flight plan set with DJI Phantom 4 Pro for each area, where the 5 missions are marked (one with a $90^{\circ}$ gimbal angle, the other 4 with $45^{\circ}$ angle directions). The flights has been set at $34 \mathrm{~m}$ high from the ground level. On the right, close range photogrammetry of urban fronts (in orange) with SLR camera and integration with data from DJI Spark for the acquisition of detail of courtyard fronts.

To design the flight plans, the DJI GSP app has been used, defining, for each of the thirteen portions, 5 inclinations of the gimbal camera (Aicardi et al. 2016), to improve the acquisition of all the fronts and the roofs of buildings (Figure 5).

In parallel, with the aim to experiment the integrated use of two UAVs and to test the metric and geometric reliability of SfM models obtained, another photographic survey campaign has been planned using a DJI spark. The use of spark, carried out on a cluster of Al-Anatreh neighborhood, has been integrated by terrestrial photogrammetry with a SLR camera. The purpose of this data integration is to take advantage of the best quality of each point cloud obtained. The experimentation was planned on a case study that allowed the application of all the digital instruments (TLS, UAVs, SLR) to check the reliability and the comparison between results (Figure. 6).

\subsection{UASs and terrestrial acquisition and post-production}

The acquisition with the DJI Phantom 4 Pro and the post production with Agisoft Photoscan 1.4.1 software generated a dense point cloud for each of the thirteen ares. The point clouds were subsequently aligned on the basis of homologous points (at least 9) identified between each pair of adjacent areas. The general model consists of 5252 cameras, 6.810.431 sparse cloud points, 175.317.270 dense cloud points and 7.055.740 polygonal faces (Figure 7).

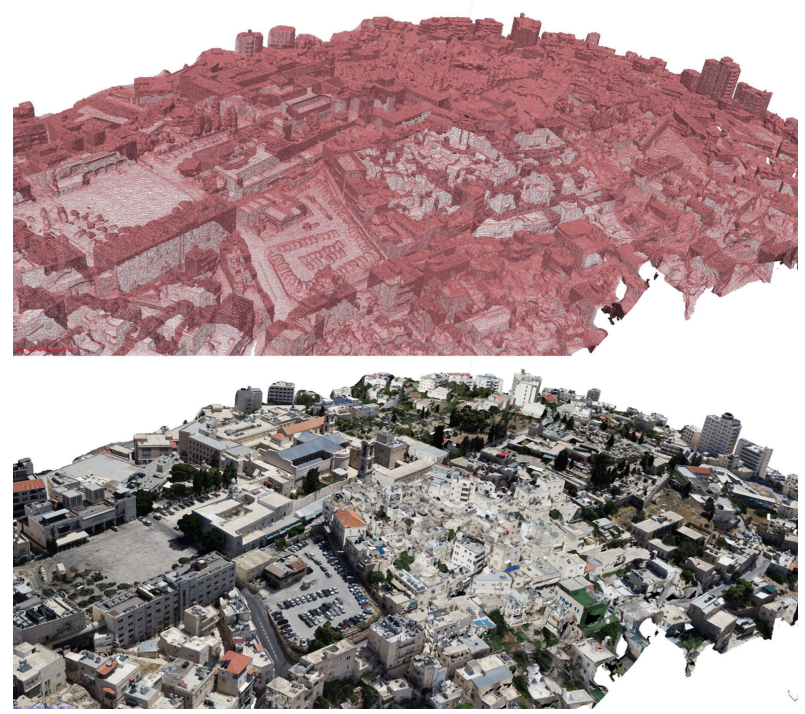

Figure 7: The Agisoft Photoscan visualization of the total 3D model in wireframe and texture mode obtained by DJI Phantom 4 Pro flight plan. 


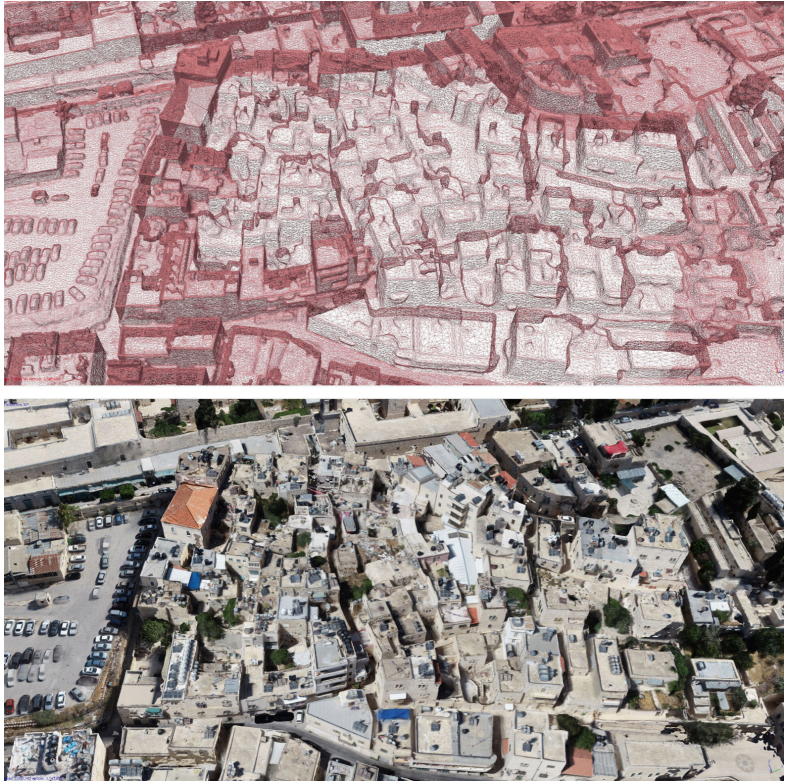

Figure 8: The Agisoft Photoscan visualization of AlAnatreh 3D model in wireframe and texture mode obtained by DJI Phantom 4 Pro flight plan.

For the area corresponding to Al-Anatreh neighborhood, the DJI Phantom 4 Pro acquired 558 images, that generated a model of 557 cameras, 248.699 sparse cloud points, 7.825.839 dense cloud points and 521.698 faces. (Figure 8).

The use of DJI Spark, which allows to get closer to the investigated surfaces of the object, has allowed to take detailed photographs of the buildings surface, obtaining a higher level of elements details. (Figure 10).

The 3D model generated from the DJI spark is constitutes by several chunks, defined by set of photographs planned around each cluster or building units (Figure 9). For an optimize data acquisition from a scheme of radial photo with convergent optical axes and at different heights has been used (Balletti et al, 2015). with this shooting methodology, it has been possible to cover the whole surface objects, trying to limit occlusions due to the conformation of the urban fabric (Figure 11).

The spark shooting mode and the arrangement around each building or clusters are also constrained by the presence of obstacle elements for the flight: antennas, satellite dish, tanks, terraces and trees define bonds that close range photogrammetry must necessarily consider to obtain a complete coverage of the object. The presence of numerous courtyard and vertical elements in the analyzed area has involved a greater number of photographs necessary to avoid occlusions or gaps in the final 3D model.

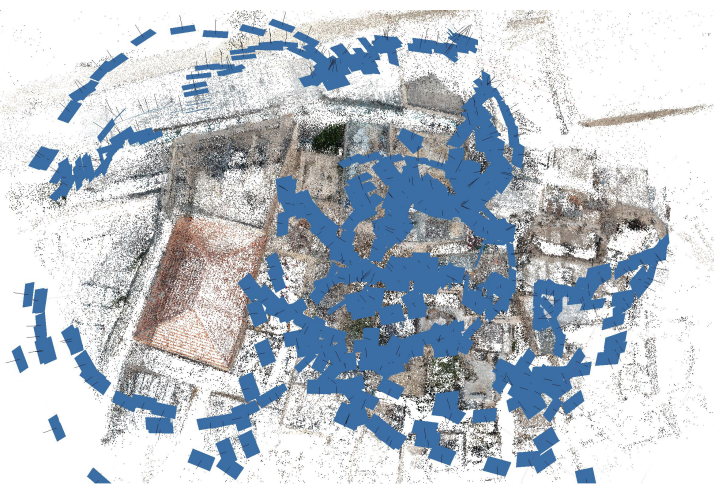

Figure 9: The Agisoft Photoscan visualization of chunks in which the cluster of Al-Anatreh neighborhood has been divided.

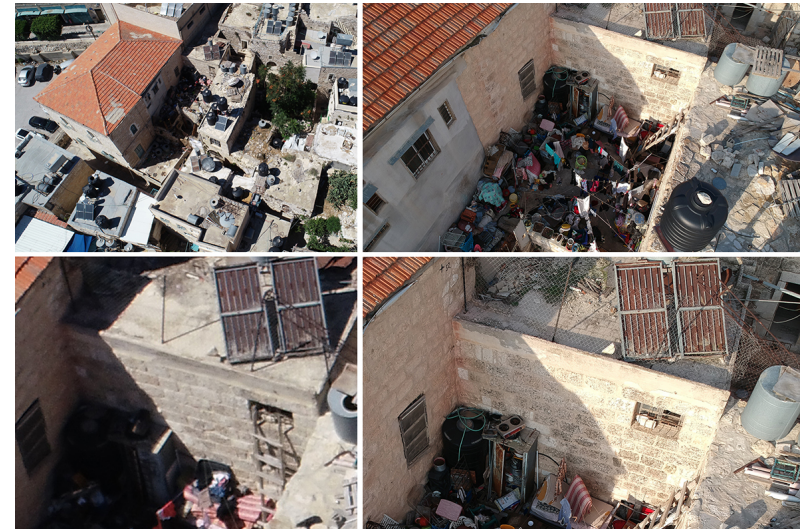

Figure 10: The different quality of the pictures from DJI Phantom 4 Pro (on the left) and DJI Spark (on the right).
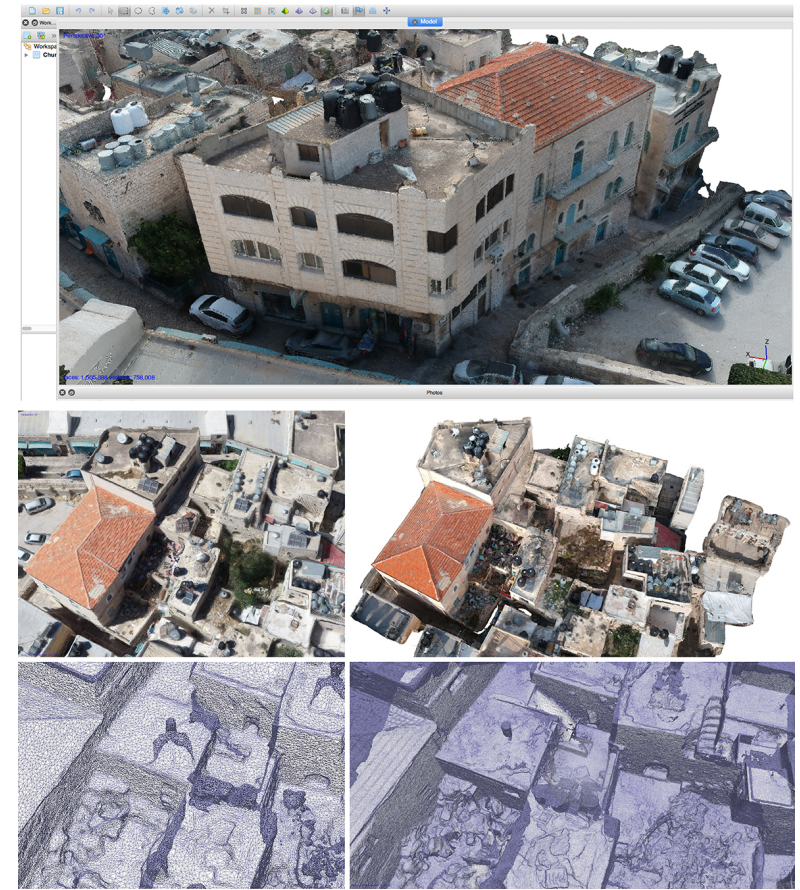

Figure 11: Above, the Agisoft Photoscan visualization of the 3D model from Spark. Below on the left, the model obtained with Phantom 4 Pro compared, on the right, with the model obtained from Spark, that presents more definition on geometrical details.
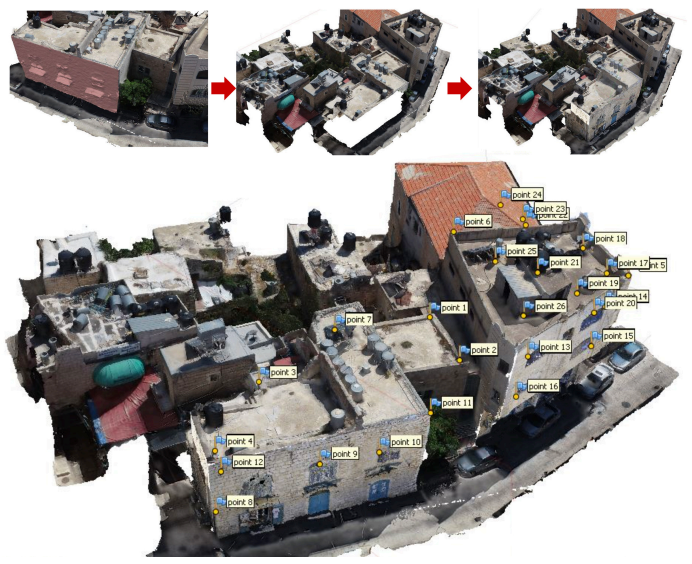

Figure 12: The fronts integration between DJI Spark and the SfM acquisition with SLR camera. 
The information of the buildings lower level, often absent or with high deformations in the model obtained from UAVs, have been integrated by specific chunks shooting from the ground level with SLR camera. The integration of a SfM campaign from the ground is necessary to the complete acquisition of an urban front: the narrow conformation of the alleys, which often do not exceed two meters in width, make difficult the data acquisition with DJI spark, which often has GPS signal problems and limited movement possibilities.

Moreover, the presence of jutting surfaces and sharp shadows on the pedestrian path and buildings don't allowed a correct photographic acquisition at medium and low altitude, which makes it necessary, in a context such as that of the historic center of Bethlehem, to integrate various photogrammetry outputs. The photogrammetric model from UAVs has been integrated to the SfM model from the ground based on homologous points on Agisoft Photoscan software. (Figure 12).

\subsection{Reliability and comparison between different UAVs output}

After the bonds analysis for the SfM acquisition campaign, it is now necessary to analyze the qualitative morphometric aspects of the point clouds and the 3D models obtained related to the use of the UAVs. The verification of the obtained geometric model allows to check the reliability of the digital SfM database and to promote comprehension about the photographic acquisition itself.

The metric tests between outputs, coming from different data acquisition systems, are made possible by the adoption of some homologous points. Often the common points are identifiable thanks to the application of targets during the acquisition campaign. Other times, as in this specific study case, putting targets becomes a long operation and not always possible, for the presence of private houses, inaccessible areas and necessity to quickly perform the survey.

The reliability of the UAVs output has been verified on the AlAnatreh neighborhood comparing the TLS point cloud and the photogrammetric point cloud: the first by DJI Phantom 4 Pro and the second by DJI Spark. To verify the geometric and metric error between the laser scanner point cloud, assumed as a reliable basis, and the drones output, the UAVs point clouds were exported by the Agisoft Photoscan software in .pts format and imported in Leica Cyclone software to be register together. The first registration (TLS and Phantom outputs) took place on the basis of well visible architectural points, common to the point clouds. The points of the context have been identified by edges or geometric structures easily recognizable both by the photographic image and by the laser scanner. For the entire area of Alnatreh (about 4.900 sq.m.) 10 homogeneously distributed targets were located on the two point clouds. The result of the point cloud overlapping has highlighted a high geometric correspondence over the horizontal extension of the area. The point cloud obtained from the Phantom seems to "cover" the buildings, approaching the surfaces, and detaching mainly on the vertical plane (Figure 13,14). The greatest critical issue encountered on the Phantom output is the lack of geometric correspondence of the buildings volumes: corners and edges lose their precision when compared with the laser scanner point cloud, let the post-production of the SfM model problematic, both for management and for virtual communication purposes. This aspect is partly solved thanks to the integration of a mini drone for inspections, as the DJI Spark. The possibility of this drone to get closer to the object and to increase the angle of camera shooting, allows to obtain a better coverage of building surfaces and a better alignment of images. As shown in figure 11, the mesh model obtained by Spark allows to better understand architectural details and the elements, even complex, present in the area. However, its use is not always possible and, in any case, very complicated. Its use needs to break up every part of the context into a series of sub-systems around which, manually, the operator moves the drone. In a complex and vast context, such as the historical center of Bethlehem, the wide use of this drone becomes difficult to imagine. The reliability tests carried out on the point cloud produced by DJI Spark on a cluster have confirmed its metric and geometric reliability, even at the scale of the building detail (Figure 15, 16, 17).
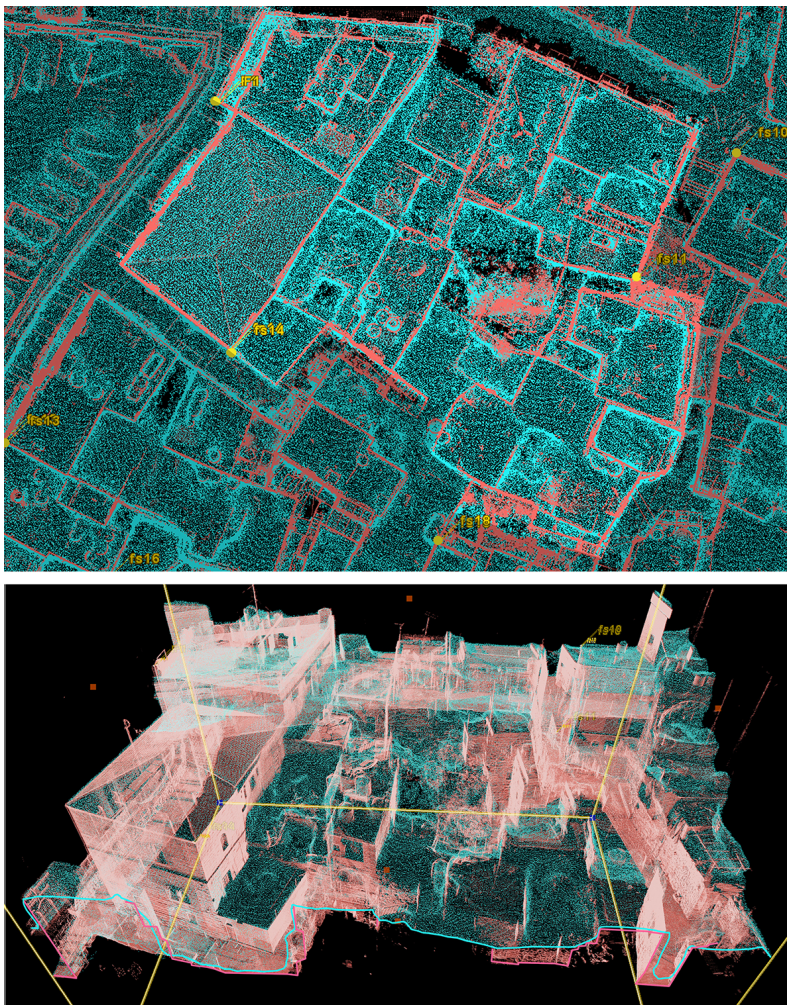

Figure 13: Overlapping of two point clouds. Reliable tests between Faro Cam 2 point cloud (red) and Phantom 4 Pro point cloud (blue).
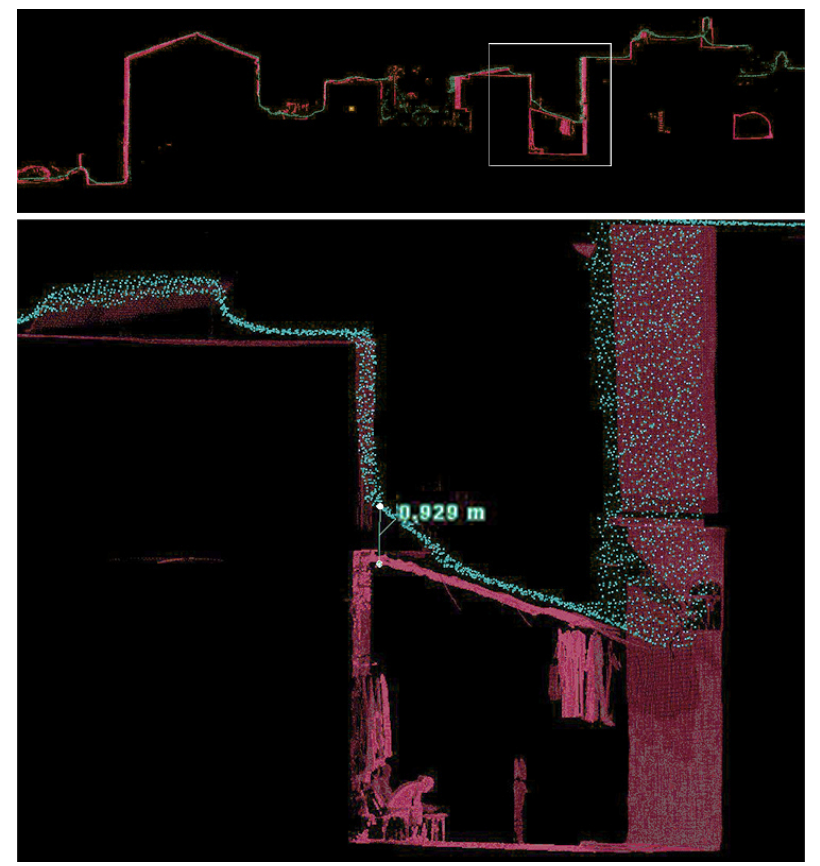

Figure 14: The reliable test on elevations and on environmental sections. The laser scanner point cloud (red) and the Phantom 4 Pro point cloud (blue). 


\section{CONCLUSIONS}

The paper analyzes the application of close range photogrammetry, aerial and terrestrial, in a specific urban context of the historical city center of Bethlehem. The preliminary analysis of the urban configuration is an operation of primary importance for the choice of the best UAVs and the optimization of the integrated photogrammetric acquisition campaign. The use of drones, as a privileged tools for the documentation procedures of the present research, is proving fundamental to this specific research project, which has the goal to realize a reliable three-dimensional model of the entire historical center. However, the huge area that must be acquired and the problems related to urban conformation have bound the photogrammetry methodological process. The application of UAVs on the historic center of Bethlehem has provided for the decomposition of the territory into environmental levels. The methodological procedures for the decomposition into macro systems, sub-systems and single elements has allowed the research team to conceive each system as an autonomous study case to acquire with integrated SfM close range photogrammetry.

The test on UAVs data acquisition, post production and reliability has been conducted on a portion of the city center, represented by a particularly complex urban agglomeration in the volumes disposition. In this portion, has been performed different flight acquisition mode, that highlighted the critical issue and potential of each drone. Both flight plans have tried to keep the camera axes as much as possible oblique, to cover difficult angles and to emulate the detailed stereopairs taken in terrestrial close range photogrammetry (Murtiyoso and Grussenmeyer, 2017).

Certainly, the outcome of point clouds obtained by drone is much more uncertain than the output obtainable from terrestrial photogrammetry. This probably depends on a minor experience of the pilots, given by the most recent use of these instruments for the architectural survey related to SfM terrestrial methodologies and equipment. It also inevitably affects a greater distance from the object to be acquired, hypothesis verified by the experimentation of the mini-UAV Spark on the same area.

The uncertainty of the final photogrammetric database implies a constant reliable test with other data, obtained from terrestrial instruments such as laser scanners or topographic instruments, able to control the value of the error and also to merge different point clouds together. The reliability test is even more decisive when multiple SfM chunks are developed and generated inside the software, as in the case of the cluster acquired with the spark drone. The alignment between chunks has been carried out by means of homologous points, attributed manually by the operator. Anyway, the metric verification of these models, compared to the TLS data gave a positive feedback.

The non-perfect geometric correspondence of the surfaces and of the volumes with regular angles and edges remains an unresolved aspect of this methodological process. A possible cause of the smoothing of the surfaces, in addition to the acquisition issues mentioned above, could be related to the software used. Probably a further verification could be the comparison between results produced by software that use different algorithms to align sets of images.

Another aspect, under experimentation, is how these models, appropriately optimized, can be semantically structured into the environmental levels in which the territory has been divided (Parrinello and Picchio, 2013). This will allowed to structure a smart 3D model of the city, able not only to guarantee a metric response and geometric on the built, but to implement the informative contents of the space for a better management and a more aware exploitation activity.

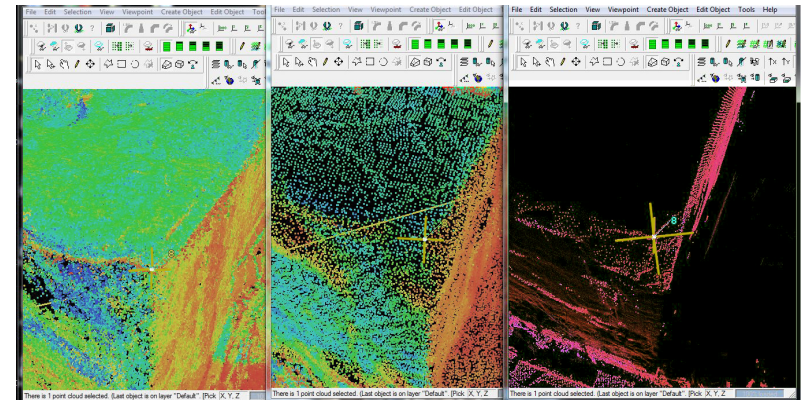

Figure 15: The registration procedure on Cyclone with manual target for the overlapping of the UAVs and TLS point clouds. From the left, the Spark point cloud, the Phantom point cloud, the Faro Cam 2 point cloud.

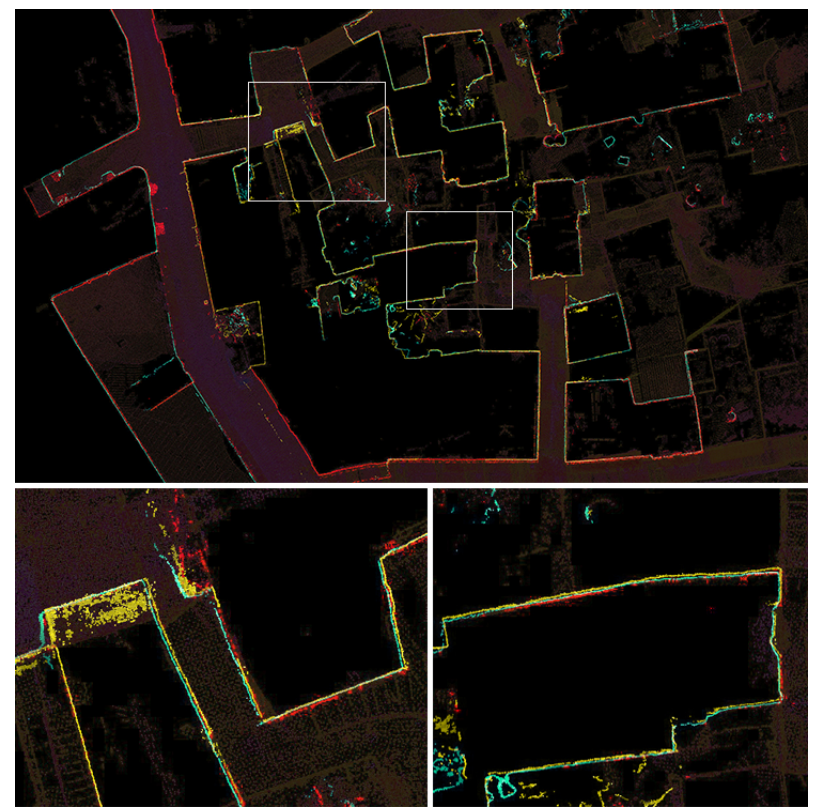

Figure 16: The results of the overlapping on Al-Anatreh' cluster. The Faro line (red), the Phantom (blue) and the Spark (yellow).
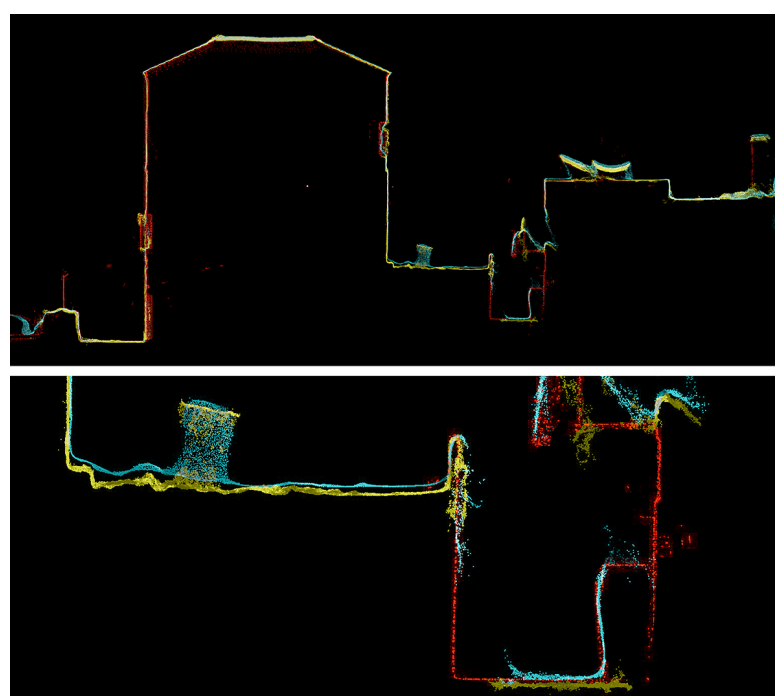

Figure 17: The overlapping on elevations. The Faro line section (red), the Phantom (blue) and the Spark (yellow). 


\section{ACKNOWLEDGEMENTS}

The research project "Management and control of urban growth for the development of heritage and improvement of life in the city of Bethlehem" (2018-2021) is coordinated by University of Pavia, DICAr, Department of Civil Engineering and Architecture in collaboration with the Municipality of Pavia and the Municipality of Bethlehem.

\section{REFERENCES}

Aicardi., I, Chiabrando, F., Grazzo, N., Lingua, A. M. and Spanò, A., 2016. UAV photogrammetry with oblique images: first analysis on data acquisition and processing. The International Archives of the Photogrammetry, Remote Sensing and Spatial Information Sciences, Volume XLI-B1, 2016. pp. 835-842.

Balletti, C., Guerra, F., Scocca, V. And Gottardi, C., 2015. 3D integrated methodologies for the documentation and the virtual reconstruction of an archaeological site. The International Archives of the Photogrammetry, Remote Sensing and Spatial Information Sciences, Volume XL-5/W4, 2015. pp. 215-222.

Caprioli, M., Mancini, F., Mazzone., F., Scarano, M. and Trizzino, R., 2015. UAV Surveys for Representing and Document the Cultural Heritage. Le Vie dei Mercanti, XIII International Forum, Vol. 56, pp. 475-482.

Chiabrando, F., Nex, F., Piatti, D., Rinaudo, F., 2011. UAV and RPV systems for photogrammetric surveys in archaelogical areas: two tests in the Piedmont region (Italy). Journal of Archaeological Science, Vol. 38, pp. 697-710.

Colomina, I. and Molina, P., 2014. Unmanned aerial systems for photogrammetry and remote sensing: a review. ISPRS J Photogramm Remote Sens, Vol. 92, pp. 79-97.

Dominici, D., Alicandro, M. and Massimi, V., 2017. UAV photogrammetry in the post-earthquake scenario: case studies in L'Aquila. In Geomatics, Natural Hazards and risk. Vol. 8, (1), pp. $87-103$.

Friz, A., Kattenborn, T and Koch, B., 2013. UAV-Based photogrammetric poin clouds. Tree stem mapping in open standards in comparison to terrestrial laser scanner point clouds. International Archives of the Photogrammetry, Remote Sensing and Spatial Information Sciences, Vol. XL-1/W2, pp.141-146.

Lo Brutto, M., Garraffa, A., Meli, P., 2014. UAV platforms for Cultural Heritage Survey: first results. ISPRS Annals of the Photogrammetry, Remote Sensing and Spatial Information Sciences, Vol. II, (5), pp. 227-234

Multiyroso, A. And Grussenmeyer, P., 2017. Documentation of Heritage Buildings using Close-Range UAV images: dense matching issues, comparison and case studies. In The photogrammetric Record. Vol. 32 (159). pp. 206-229.

Nex, F. And Remondino, F., 2013. UAV for 3D mapping applications: a review. Appl Geomat. Vol. 6, pp. 1-15.

Parrinello, S. and Picchio, F., 2013. From digital photography to the 3D model of historical architecture. Disegnare Con, Vol.6. pp. $29-42$.

Parrinello, S. and Picchio, F., 2014. Recomposing the landscape using Structure from Motion survey in the village of Korza,
Karelia (Russia). SCIentific RESearch and Information Technology, Vol 4, Issue 2, pp. 29-42.

Remondino, F., Barazzetti, L., Nex, F., S. Caioni, M. Sarazi, D. UAV photogrammetry for mapping and $3 \mathrm{D}$ modelling-current status and future perspectives. ISPRS - Int. Arch. Photogramm. Remote Sens. Spatial Inform. Sciences. Vol. XXXVIII-1/C22, pp. 25-31.

Rinaudo, F., Chiabrando, F., Lingua, A. and Spanò, A., 2012. Archsaeological site monitoring: UAV photogrammetry can be an answer. International Archives of the Photogrammetry, Remote Sensing and Spatial Information Sciences, Volume XXXIX-B5, pp. 583-588.

Tang, L. and Shao, G., 2015. Drone remote sensing for forestry research and practices. J. For. Res. Northeast Forestry University and Springer-Verlag Berlin Heidelberg. Vol. 26 (4), pp. 791797.

Themistocleous, K., Ioannides, M., Agapiou, A. and Hadjimitsis, D.G., 2015. The Methodology Of Documenting Cultural Heritage Sites Using Photogrammetry, UAV And 3D Printing Techniques: The Case Study Of Asinou Church in Cyprtus. Proceedings of SPIE - The International Society for Optical Engineering. Vol. 9535. 